\title{
Seasonal rhythms of vasopressin release and aquaporin-2 excretion assure appropriate water conservation in humans
}

\author{
Nandu Goswami ${ }^{1}$ Annarita Di Mise², Mariangela Centrone², Annamaria Russo², Marianna Ranieri², \\ Johann Reichmuth', Bianca Brix', Natale Gaspare De Santo ${ }^{3}$, Ferdinando Carlo Sasso ${ }^{3}$, Grazia Tamma ${ }^{2}$ and \\ Giovanna Valenti ${ }^{2 *}$ (0)
}

To the Editor,

Regulation of water balance is essential for life. It depends on water intake and water excretion and is regulated by the antidiuretic hormone vasopressin (AVP). AVP is released from the hypothalamus in response to an increase in plasma osmolality or a decrease in blood volume. AVP binds to the V2 receptor expressed in the basolateral membrane of renal collecting duct principal cells. It activates a Gs protein causing an increase in intracellular cAMP leading to a protein kinase A (PKA) mediated translocation of the Aquaporin-2 (AQP2) water channel to the apical membrane of collecting duct principal cells thus promoting water reabsorption and urine concentration [1-3]. In addition to short term regulation of AQP2 trafficking, AVP regulates the total AQP2 abundance within the cell and modulates AQP2 half-life $[4,5]$. Alterations in the AQP2 abundance as well as defects in AVP signaling in the renal collecting duct can compromise the renal function and the maintenance of water balance in the body.

The distribution of water in different body compartments is influenced by variations of environmental

\footnotetext{
*Correspondence: giovannavalenti@uniba.it

2 Department of Biosciences, Biotechnologies and Biopharmaceutics, University of Bari Aldo Moro, Via Orabona, 4, 70125 Bari, Italy

Full list of author information is available at the end of the article
}

temperatures implying that seasonal fluctuations in AVP release should occur to maintain constant plasma osmolality. While seasonal fluctuations of several hormones have been reported [6], to our knowledge, a detailed measurement of seasonal rhythm of AVP in humans (males and females) and its correlation with AQP2, has never been investigated.

To this end, young healthy men and women between 18 and 30 years were enrolled at the Division of Physiology, Medical University of Graz in cold (November-March) and warm (April-October) months. The local ethics committee approved this study. All participants gave written consent. To minimize circadian influences on cardiovascular variables, the study was conducted between 9 a.m. and 1 p.m. The participants were fasting and urine were collected from each participant. The investigations were carried out in quiet room maintained at $23-25{ }^{\circ} \mathrm{C}$ and humidity between 50 and 55\%. Blood was collected during 30-min rest phase for AVP measurements.

We have previously shown [7] that, compared with females, males have a roughly $40 \%$ higher baseline AVP, measured as copeptin, a surrogate biomarker for plasma AVP. We observed a significant effect of seasonal rhythms on baseline AVP levels in both males and females. Considering all tested participants, AVP was found to be significantly higher in the warmer season as compared to the colder season $(2.199 \pm 0.2380$ vs $1.066 \pm 0.078 \mathrm{pg} / \mathrm{ml}$, $\mathrm{n}=52 ; \mathrm{p}<0.0001$, Fig. 1a). The difference in AVP was also maintained when the participants were grouped as males and females (males: $2.437 \pm 0.2578$ vs $1.144 \pm 0.087 \mathrm{pg} /$

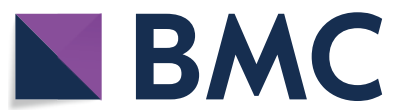

(c) The Author(s) 2021. This article is licensed under a Creative Commons Attribution 4.0 International License, which permits use, sharing, adaptation, distribution and reproduction in any medium or format, as long as you give appropriate credit to the original author(s) and the source, provide a link to the Creative Commons licence, and indicate if changes were made. The images or other third party material in this article are included in the article's Creative Commons licence, unless indicated otherwise in a credit line to the material. If material is not included in the article's Creative Commons licence and your intended use is not permitted by statutory regulation or exceeds the permitted use, you will need to obtain permission directly from the copyright holder. To view a copy of this licence, visit http://creativeco mmons.org/licenses/by/4.0/. The Creative Commons Public Domain Dedication waiver (http://creativecommons.org/publicdomain/ zero/1.0/) applies to the data made available in this article, unless otherwise stated in a credit line to the data. 

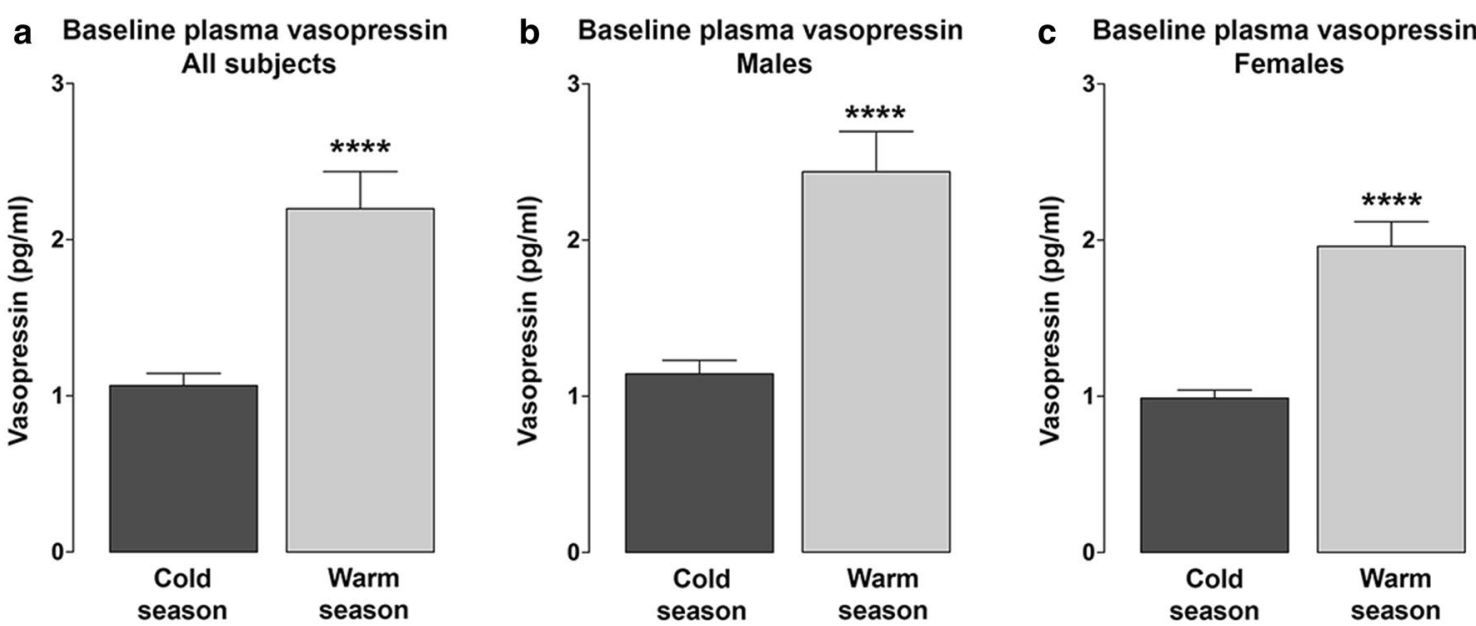

Fig. 1 Comparison of baseline plasma AVP in the cold and warm seasons expressed as pg/ml. Plasma vasopressin was determined using a competitive RIA kit (Vasopressin; Nichols Institute Diagnostics, San Juan Capistrano, CA, USA). a AVP was significantly higher in the warm season (April-October) as compared with the cold season (November-March) in all participants, ${ }^{* * *} \mathrm{p}<0.0001, \mathrm{n}=52 . \mathbf{b}$ In males, AVP was significantly higher in the warm season respect to the cold season, ${ }^{* * * *} \mathrm{p}<0.0001, n=24$. c Similarly, in females, AVP was significantly higher in the warm season with respect to the cold season ${ }^{* * * *} p<0.0001, n=28$. Values are expressed as means $\pm S E M$. Student's t-test was used for the statistical analysis

$\mathrm{ml}, \mathrm{n}=24, \mathrm{p}<0.0001$, Fig. 1b; females: $1.961 \pm 0.156$ vs $0.988 \pm 0.051 \mathrm{pg} / \mathrm{ml}, \mathrm{n}=28, \mathrm{p}<0.0001$, Fig. 1c). Therefore, in the warmer season, AVP values were almost twofold higher in both sexes, although the males displayed absolute higher values in both seasons.

The AVP data were positively correlated with urinary AQP2 (u-AQP2) excretion, the water channel regulated by AVP. AQP2 excretion through exosomes is proportional to its expression in the kidney and in the luminal membrane of collecting duct principal cells, representing a useful biomarker for the renal response to AVP [8].

Similar to AVP levels, a significant effect of seasonal rhythms on baseline AQP2 excretion (u-AQP2) was also observed in males and females. In all tested participants, $\mathrm{u}-\mathrm{AQP} 2$ was found significantly higher in the warmer season as compared to the colder season $(3732 \pm 273.6$ vs $2388 \pm 279.8 \mathrm{fmol} / \mathrm{mg} \mathrm{n}=52, \mathrm{p}<0.01$, Fig. $2 \mathrm{a})$. This significant difference was maintained when males and
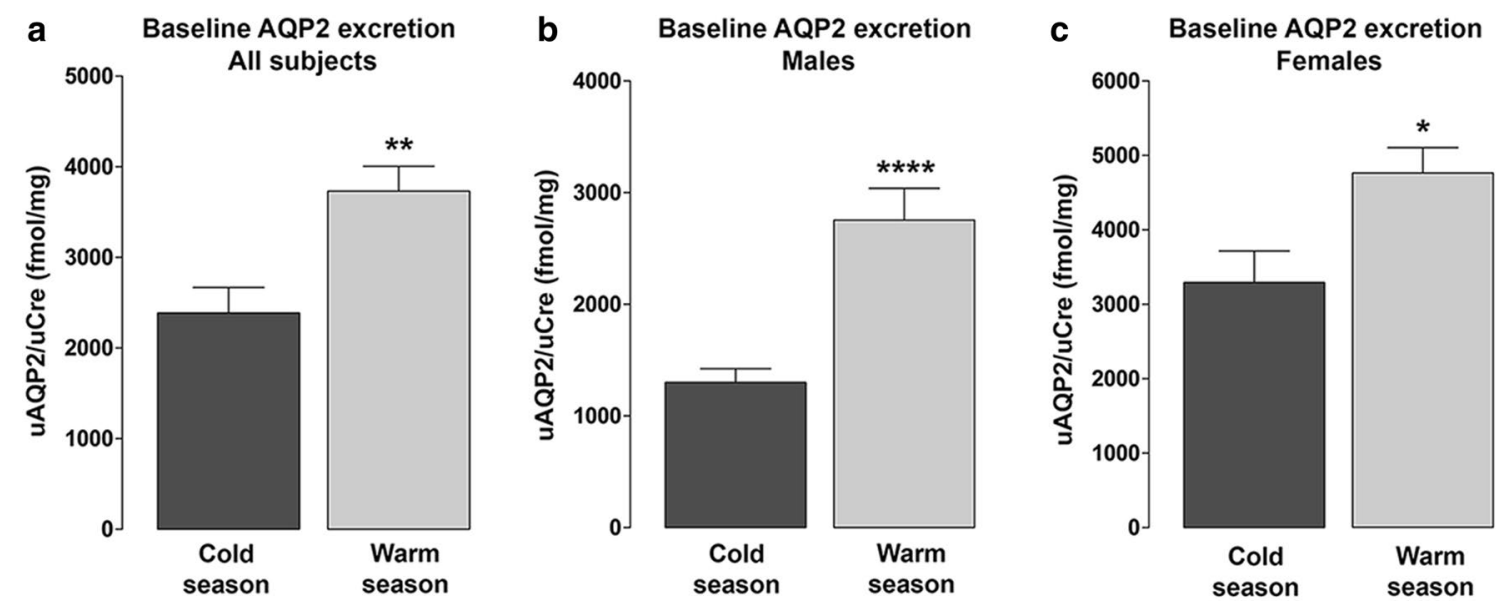

Fig. 2 Comparison of baseline urinary levels of aquaporin-2 (U-AQP2) in the cold (November-March) and warm seasons (April-October), expressed as protein to-urinary creatinine ratio (U-AQP2/uCre, fmol/mg). Urinary AQP2 excretion was measured in the urine samples by ELISA as previously described [10]. a u-AQP2 excretion was significantly higher in the warm season respect to the cold season in all participants, ${ }^{* *} p<0.01, n=52$. $\mathbf{b}$ In males, U-AQP2 excretion was significantly higher in the warm season respect to the cold season, ${ }^{* * * *} p<0.0001, n=24$. $\mathbf{~ I n ~ f e m a l e s , ~} \mathrm{u}-\mathrm{AQP} 2$ excretion was significantly higher in the warm season respect to the cold season, ${ }^{*} p<0.05, n=28$. Values are expressed as means $\pm S$.E. Student's t-test was used for the statistical analysis 
females were considered separately in the warmer and in the cold seasons (males: $2756 \pm 282.7$ vs $1302 \pm 121.4$ $\mathrm{fmol} / \mathrm{mg}, \mathrm{n}=24, \mathrm{p}<0.0001$, Fig. 2b; females: $4762 \pm 338.8$ vs $3294 \pm 423.9, \mathrm{fmol} / \mathrm{mg}, \mathrm{n}=28, \mathrm{p}<0.05$, Fig. 2c). As observed for AVP, u-AQP2 values nearly doubled in males in the warmer season whereas in females the significant increase in $\mathrm{u}-\mathrm{AQP} 2$ in the warmer season was slightly less pronounced (approx. 1.5-fold).

Overall, the observed seasonal adaptations of AVP and $\mathrm{u}-\mathrm{AQP2}$ are fully consistent with the need for greater water reabsorption in the warmer season due to increased sweating, which is associated with a loss of a significant amount of water. Moreover, in addition to stimulation of AQP2 trafficking, AVP also stimulates thirst, which leads to additional fluid intake [9].

In conclusion, we provide for the first time, a comprehensive analysis of seasonal rhythms of AVP release in humans that correlate with urinary AQP2 excretion. Specifically, plasma AVP levels are nearly double in the warmer season compared with the colder season both in males and females and these seasonal fluctuations correlate with parallel modulation in AQP2 excretion. These data indicate that, in warm season, when risk of dehydration is higher, plasma AVP is increased to assure appropriate water conservation though activation of AQP2 trafficking to the luminal membrane of the collecting duct principal cells, as reflected by higher AQP2 excretion.

\section{Acknowledgements}

None.

\section{Authors' contributions}

$A D M, M C, A R, M R, J R, B B$ performed the experiments and contributed to data analysis and manuscript preparation. NG, GT, NGD, FS and GV conceived of the study and contributed to data analysis and manuscript preparation. All authors read and approved the final manuscript.

\section{Funding}

This work was supported by the "Endothelial unction and Renal, vascular and neuroendocrine responses during Orthostatic Syncope and recover: comparison between sexes" (EROS) project, sponsored by the Italian Space Agency (Agenzia Spaziale Italiana). ADM is supported by "Attrazione e Mobilità dei Ricercatori, PON "R\&l" 2014-2020, Azione I.2". Attrazione e Mobilità dei Ricercatori, PON "R\&l" 2014-2020, Azione I.2 (code AIM1893457 - 3, linea 1).

\section{Availability of data and materials}

The datasets generated during and/or analysed during the current study are available from the corresponding author on reasonable request.

\section{Declarations}

Ethics approval and consent to participate The local ethics committee at the University of Graz approved this study. All participants gave written consent.
Consent to publish

All authors give their consent to publish this manuscript.

\section{Competing interests}

The authors declare that they have no competing interests.

\section{Author details}

${ }^{1}$ Physiology Division, Otto Loewi Center of Research in Vascular Biology, Immunity and Inflammation, Medical University of Graz, Graz, Austria. ${ }^{2}$ Department of Biosciences, Biotechnologies and Biopharmaceutics, University of Bari Aldo Moro, Via Orabona, 4, 70125 Bari, Italy. ${ }^{3}$ Department of Advanced Medical and Surgical Sciences, Università Della Campania "L. Vanvitelli", Viale Lincoln, 5, 81100 Caserta, Italy.

Received: 7 April 2021 Accepted: 24 April 2021

Published online: 05 May 2021

\section{References}

1. Ranieri M, Di Mise A, Tamma G, Valenti G. Vasopressin-aquaporin-2 pathway: recent advances in understanding water balance disorders. J Res. 2019. https://doi.org/10.12688/f1000research.16654.1.

2. Tamma G, Lasorsa D, Ranieri M, Mastrofrancesco L, Valenti G, Svelto M. Integrin signaling modulates AQP2 trafficking via Arg-Gly-Asp (RGD) motif. Cell PhysiolBiochem. 2011;27(6):739-48.

3. Fenton RA, Murali SK, Moeller HB. Advances in Aquaporin-2 trafficking mechanisms and their implications for treatment of water balance disorders. Am J Physiol Cell Physiol. 2020. https://doi.org/10.1152/ajpcell. 00150.2020.

4. Sandoval PC, Claxton JS, Lee JW, Saeed F, Hoffert JD, Knepper MA Systems-level analysis reveals selective regulation of Aqp2 gene expression by vasopressin. Sci Rep. 2016;6:34863.

5. Wu Q, Moeller HB, Stevens DA, Sanchez-Hodge R, Childers G, Kortenoeven MLA, et al. CHIP regulates aquaporin-2 quality control and body water homeostasis. J Am SocNephrol. 2018;29(3):936-48.

6. Schmitt CP, Hömme M, Schaefer F. Structural organization and biological relevance of oscillatory parathyroid hormone secretion. PediatrNephrol. 2005;20(3):346-51.

7. Goswami N, Reichmuth J, Di Mise A, Brix B, Roessler A, Centrone M, et al. Comparison between men and women of volume regulating hormones and aquaporin-2 excretion following graded central hypovolemia. Eur J ApplPhysiol. 2019;119(3):633-43.

8. Valenti G, Laera A, Pace G, Aceto G, Lospalluti ML, Penza R, et al. Urinary aquaporin 2 and calciuria correlate with the severity of enuresis in children. J Am SocNephrol. 2000;11(10):1873-81.

9. Malisova O, Athanasatou A, Pepa A, Husemann M, Domnik K, Braun H, et al. Water intake and hydration indices in healthy European adults: The European Hydration Research Study (EHRS). Nutrients. 2016;8(4):204.

10. Tamma G, Di Mise A, Ranieri M, Svelto M, Pisot R, Bilancio G, et al. A decrease in aquaporin 2 excretion is associated with bed rest induced high calciuria. J Transl Med. 2014;12:133.

\section{Publisher's Note}

Springer Nature remains neutral with regard to jurisdictional claims in published maps and institutional affiliations. 